\title{
计算机科学技术在计算机教育中的应用
}

\section{Application on Computer Science and Technology in Computer Education}

\section{刘运涛 \\ Yuntao Liu}

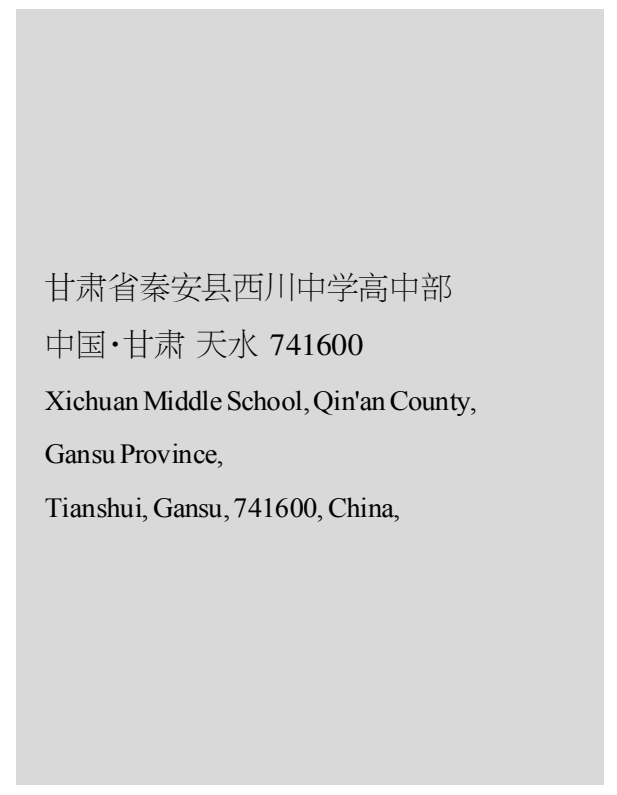

【摘要】现阶段,随着计算机应用知识的不断普及, 计算机应用能力掌握逐渐成为现代人 基本的技能、素质标志。在高中教育课程改革实施的过程中,计算机逐渐成为一门必须学 课程, 其具有现代科技特点, 有助于提高学生的思维能力, 培养更多应用型人才, 论文主要 针对计算机科学技术在计算机教育中的应用进行了分析。

【Abstract】At present, the knowledge of computer application is gradually being popularized, computer application ability has gradually become a basic skill and quality symbol of modern people. In the process of curriculum reform and implementation of high school education, computer has gradually become a must-learn course, which has the characteristics of modern science and technology, which is helpful to improve students' thinking ability and cultivate more applied talents. The article mainly analyzes the application of computer science and technology in computer education.

【关键词】计算机科学技术; 计算机教育; 应用

【Keywords】computer science and technology; computer education; application 【DOI】10.36012/sde.v2i4.1836

\section{1 引言}

在现代化建设和改革过程中, 社会各界越来越关注计算 机技术相关产业的发展, 计算机教师需要创新并优化现有的 计算机教学模式, 为计算机课程教学的有效性提供支持。在新 时期高中计算机教学过程中, 教师需要引进计算机科学技术, 强化学生实践能力培养, 引导学生将计算机教学内容渗透到 日常生活中。基于此, 本文阐述了高中计算机教育的重要性, 分析了计算机科学技术在计算机教育中的应用优势, 总结了 高中计算机课教学问题及计算机科学技术的应用。

\section{2 高中计算机教育的重要性}

在高中时期教育教学过程中, 计算机教学逐渐成为教学 的重点内容, 计算机技术是一项热门技术, 社会各界对计算机 人才的需求量日益增加, 计算机操作技术是高中教育教学的 重点, 教育部门越来越关注计算机教育工作, 教师需要合理地 设置计算机课程, 引导学生积极参与到教学全过程中 ${ }^{[1]}$ 。高中 时期是学生学习的关键阶段, 计算机是高中教学中的重点课 程, 但在实际教学中, 教师逐渐认识到传统教育模式对现代教

【作者简介】刘运涛(1978 ), 男, 甘肃秦安人, 一级教师, 从事计算 机科学教育专业研究。
育带来的影响, 并对其进行了有效改革, 满足了现代化教学的 预期要求。在素质教育教学背景下,计算机教学的主要目标是 培养学生的计算机操作能力, 积极转变现有的教学理念, 针对 计算机教学模式进行创新和优化, 深入分析高中教育教学的 特点、实际要求, 不能强迫学生, 为学生营造趣味性的高中计 算机课堂, 这样学生从计算机课堂中得以锻炼。

\section{3 计算机科学技术在计算机教育中的应} \section{用优势}

\section{1 促进师生交流}

在高中教育教学过程中, 计算机教学发展十分迅速, 但很 多教师仍实行传统的教学模式, 这样学生很少有机会参与实 践, 导致教师和学生之间的交流越来越少, 很难提升高中计算 机教学的整体水平。为了有效地改善这一现状, 很多教师引进 了计算机科学技术, 根据现代化教学进行改革和发展。通过计 算机网络教学为教师和学生构建交流、沟通的平台, 教师和学 生通过利用网络视频教学功能, 改变了传统教学中教师和学 生交流障碍问题, 实现了教师和学生交流的高效性。

\section{2 提升自主学习能力}

在传统的高中计算机教育中, 学生普遍模仿教师的课程 步骤, 逐步完成教学任务, 这种方式很难提升学生的自主学习 
教育理论与研究 Educational Theory and Research

能力, 严重阻碍了高中计算机教学活动的改革和创新 ${ }^{[2]}$ 。为了 有效地改善这一现状,教师需要引进现代计算机技术,引导学 生进行自主学习、无场景障碍学习, 充分利用网络资源进行教 学, 大力拓展教学内容, 扩展学生的知识面, 确保计算机技术 教学的规范性、全面性。

\section{4 高中计算机课程教学中存在的问题}

\section{1 不注重计算机教育}

在高中时期教育教学过程中, 教师缺乏对计算机教育重 要性的认识, 严重影响着计算机教学的整体质量, 而中国高中 教育教学工作在学生成长、发展中发挥着重要作用,教师必须 确保教学内容的多样性, 提高学生的综合素质。但是,受升学 压力等各项因素的影响, 高中学校普遍注重数学、语文、英语 等主要基础课程,缺乏对其他学科的重视,严重阻碍了计算机 教育活动的有效开展。

\section{2 缺乏实践操作机会}

在高中计算机教学过程中, 教师需要注重学生计算机操 作能力、计算机水平的培养, 为学生学习、生活提供更多便利, 在实际教学过程中, 教师必须认识到实践操作的重要性, 不能 过度强调理论知识。但是, 在新时期高中计算机教育过程中, 教师安排的上机课比重存在很大偏差, 一般三四堂课中开放 一次上机操作, 无法有效地提升学生的操作能力, 严重影响着 学生对计算机实践操作的掌握, 阻碍了计算机教育活动的有 效开展。

\section{3 教学模式对计算机教学质量的影响}

为了提高教育教学的整体质量, 教师必须引进现代化教 学模式,引导学生积极参与到课程教学中。但是, 在高中计算 机实际教学中,教师未建立创新型教育教学模式,阻碍了计算 机教学活动的有序开展, 很多教师普遍实行传统的教育教学 模式,教师只注重对理论知识的讲解,学生记录计算机教学的 相关知识,这种枯燥、乏味的计算机教育教学形式,无法激发 学生的学习兴趣, 且教学内容具有一定的复杂性, 教师未向学 生提供更多操作实践的机会, 导致教学知识很难进行巩固和 加强,无法提升学生的计算机水平。

\section{5 计算机科学技术在计算机教育中的应用}

\section{1 在计算机教学管理中的应用}

在计算机教育教学中,教学质量和效果具有重要作用,教 师必须予以重视,充分利用计算机技术进行教学管理工作, 有 效地提升计算机教育教学管理的整体效果。一般而言,教学管 理主要涉及两方面内容, 分别是学生日常学习的了解和监控、
学生的成绩监测和日常行为管理。在科学技术水平快速提升 的大背景下, 计算机管理教学逐渐成为一种学习系统, 缓解了 教师的学习压力, 使教师的教学水平得到了很大的提升。

\section{2 丰富教育教学资源}

在新课程教育教学改革的大背景下, 教师需要认识到计 算机教育的重要性, 通过计算机科学技术进行计算机课程教 学活动, 还可以利用网络信息渠道, 丰富计算机教育教学资 源, 有效地将计算机科学技术渗透到教学全过程中, 以满足现 代化教育教学创新的实际要求。在新时期的计算机教育过程 中,教师需要引导学生利用互联网观看学习视频,在课余时间 通过播放视频进行学习, 这样就能够获取丰富的教学资源, 确 保计算机课堂教学的灵活性、直观性, 为学生更好地掌握计算 机教学知识提供支持, 通过计算机科学技术获取海量的教育 教学资源, 可以节省更多的教学成本。例如, 在高中计算机考 试过程中, 教师可以将准备的纸张材料转变成电子材料, 将学 生考试的笔试内容转变成计算机考试,节省更多的纸张, 减少 人力资源、物力资源的投入力度, 降低所需成本。除此之外, 在 高中计算机教学过程中, 教师需要充分利用网络渠道进行教 学, 丰富学生的学习内容, 为学生节省更多的学习时间, 并创 建多样性的学习机制。

\section{3 明确高中计算机教学方向}

在高中计算机教育教学过程中, 教师需要深入分析教学 的实际情况，合理地制订教学计划。信息技术课程具有一定的 灵活性、实用性, 高中教师普遍注重计算机教学基础,引导学 生普及计算机教学内容, 使学生深人了解计算机工作原理, 为 未来学习专业计算机知识夯实基础。除此之外,教师需要注重 学生实践操作能力的培养,计算机属于辅助工具, 为学习其他 学科提供了支持。在实际教学中, 教师需要认识到计算机工具 的作用,为学生的学习、工作提供基础支持。

\section{6 结语}

综上所述, 在新时期的高中计算机教学过程中, 教师逐渐 认识到计算机教育的重要性, 更加关注计算机教育的实践性、 综合性, 在实际教学中为学生提供了更多的时间, 明确学生在 课堂中的主体地位, 有助于激发学生的学习积极性, 践行素质 教育理念, 提高学生的计算机水平。

\section{参考文献}

[1]李鹏.关于计算机课堂教学存在的问题和对策 [J].电脑知识与 技术,2019,15(31):138-139.

[2]张莉. 把握新时代计算机教育科学研究新机遇[J].计算机教育, 2018(5):20-25 